\title{
PENENTUAN ALOKASI PESANAN BAHAN BAKU DENGAN INTEGRASI METODE FUZZY-TOPSIS DAN MULTI CHOICE GOAL PROGRAMMING DI PT. DJARUM KUDUS
}

\author{
Diana Puspita Sari \\ Fakultas Teknik, Program Studi Teknik Industri \\ Universitas Diponegoro \\ Email: diana_psptsr@yahoo.com \\ Darminto Pujotomo \\ Fakultas Teknik, Program Studi Teknik Industri \\ Universitas Diponegoro \\ Roosita Maryani \\ Fakultas Teknik, Program Studi Teknik Industri \\ Universitas Diponegoro
}

\begin{abstract}
ABSTRAK
PT. Djarum Kudus mengalami keterlambatan bahan baku dan terdapat bahan baku yang defect, salah satunya yaitu bahan baku penunjang kemasan yaitu plat bos. Plat bos memiliki performansi yang buruk dibandingkan dengan bahan baku lainnya serta memiliki dampak bagi perusahaan yaitu salah satunya dapat terjadi putus produksi. Di mana supplier untuk bahan baku plat bos yaitu supplier A, B, C, dan D. Oleh karena itu perlu dilakukan penentuan prioritas supplier untuk menentukan alokasi pesanan kepada supplier guna mendapatkan bahan baku yang berkualitas dan tidak mengalami keterlambatan pengiriman bahan baku. Permasalahan pengambilan keputusan yang optimal yaitu dalam menentukan prioritas supplier dan alokasi order. Untuk mengatasi permasalahan tersebut dalam penelitian ini menggunakan integrasi metode fuzzy-TOPSIS dan MCGP (Multi Choice Goal Programming). Kriteria tertinggi pertama adalah kriteria ketepatan waktu, kriteria tertinggi kedua adalah kriteria kualitas, dan kriteria tertinggi ketiga adalah kriteria kapasitas produksi dan kriteria yang terendah adalah kriteria lokasi. Hasil urutan prioritas pemilihan supplier didapat dari metode fuzzy-TOPSIS dengan urutan prioritas supplier C, D, A, dan B dan alokasi pesanan didapat dari pengolahan data dengan menggunakan metode MCGP.
\end{abstract}

Kata kunci: bahan baku, alokasi pesanan, kriteria, fuzzy-TOPSIS, MCGP.

\section{ABSTRACT}

PT. Djarum Kudus has problems raw material delay and defect, such as raw material which is plat bos. Plat bos has poor performance than other raw materials and has impact on the company that is break production. Suppliers plat bos that are supplier A, B, C, and D. Therefore company needs to determine supplier priority to get good raw material and not occur delay in delivery raw material. The problems optimum decision making that is determine supplier priority and order allocation. To solve the problems in this paper by method of integrated fuzzy-TOPSIS and MCGP (Multi Choice Goal Programming). The first criteria is on time delivery, the second criteria is quality, and the third criteria is production capacity, and the last criteria is location. The result priority of supplier selection by fuzzyTOPSIS method are supplier C, D, A, and B and order allocation is obtained by MCGP method.

Keywords: raw material, order allocation, criteria, fuzzy-TOPSIS, MCGP.

\section{PENDAHULUAN}

Industri rokok merupakan salah satu industri yang memiliki peranan relatif besar terhadap penerimaan negara. Dalam memenuhi permintaan pasar terhadap produk rokok tentunya persaingan antar perusahaan yang memproduksi rokok harus memiliki strategi agar dapat bersaing dengan perusahaan lainnya, salah satunya dengan memproduksi rokok yang berkualitas baik agar konsumen merasa puas dengan produk tersebut dan dapat memenuhi permintaan konsumen dalam jumlah yang tepat. Produk yang berkualitas salah satunya dengan bahan baku yang baik, untuk mendapatkan bahan baku yang baik diperoleh dari supplier yang baik. Sedangkan pemenuhan produk dalam jumlah yang tepat tentunya proses produksi harus berjalan lancar dan baik sehingga tidak boleh terjadi keterlambatan bahan baku yang berkualitas baik tentunya. Oleh karena itu perlu dilakukan penentuan 
prioritas supplier untuk menentukan alokasi pesanan kepada supplier guna meningkatkan kompetitif perusahaan dan meningkatkan kepuasan pelanggan dengan memberikan produk yang berkualitas baik dan sesuai permintaan konsumen. Penentuan prioritas supplier merupakan permasalahan multi kriteria yang melibatkan faktor atau kriteria kualitatif dan kuantitatif. Sehingga Penentuan prioritas supplier menjadi sangat penting dikarenakan bahan baku dan komponen dapat mencapai 70\% dari biaya produk dalam industri manufaktur [1].

PT. Djarum merupakan salah satu perusahaan nasional yang memproduksi rokok. PT. Djarum mempunyai 25 brand yang dibagi menjadi tiga golongan yaitu SKM, SKT, dan cerutu. Sistem produksi PT. Djarum adalah menggunakan sistem pull, di mana PT. Djarum memproduksi rokok sesuai dengan permintaan pasar. Oleh karena itu strategi purchasing berperan penting dalam memenuhi kebutuhan produksi PT. Djarum. Sehingga dalam hal pemenuhan bahan baku agar dapat memproduksi rokok sesuai perencanaan diperlukan adanya kerjasama dengan pihak supplier. Bahan baku yang diambil sebagai objek penelitian adalah bahan baku penunjang berupa kemasan yaitu plat bos. Bahan baku utama seperti tembakau dan cengkeh tidak ada masalah dalam performansi. Plat bos adalah bahan penunjang yang masuk dalam kategori wrapping. Plat bos adalah sejenis identitas rokok untuk masing-masing brand yang berfungsi sebagai perekat bungkus rokok yang dimasukan ke dalam bal. Plat bos adalah bahan baku yang memiliki performansi buruk di antara bahan baku penunjang kemasan lainnya karena sering terjadi keterlambatan dan tingkat kecacatan tinggi, hal ini berdampak pada terjadinya putus produksi. Supplier plat bos ada 4 yaitu supplier A, B, C, dan D. Bahan baku plat bos terdapat 29 jenis, namun berdasarkan performansi terdapat empat plat bos yang memiliki performansi terburuk berdasarkan ketidaktepatan waktu pengiriman bahan baku dan kecacatan bahan baku yang tinggi yaitu plat bos DC 12 IDN R1, plat bos DCX 12 IDN, plat bos SPR 12 IDN, dan plat bos BLKML 16 IDN

Berdasarkan permasalahan di atas, maka penelitian ini bertujuan untuk memilih dan menentukan urutan prioritas supplier dan kemudian mengalokasikan order sesuai dengan prioritas supplier yang telah ditentukan dengan menggunakan metode fuzzy TOPSIS (Technique for Others Preferance by Similarity to Ideal Solution) dan MCGP (Multi Choice Goal Programming). Metode fuzzy TOPSIS untuk pemilaian tentang kriteria intangible dari masing-masing supplier dengan mempertimbangkan parameter untuk mengukur syarat masing-masing supplier. Sedangkan metode MCGP untuk menggabungkan faktor kualitatif dan faktor kuantitatif dengan menerapkan CCi sebagai koefesien fungsi objektif dalam MCGP. Sehingga MCGP mendapatkan supplier terbaik dengan adanya batasan jumlah kapasitas dan demand. Hasil dari fuzzy TOPSIS tanpa memperhatikan kapasitas supplier, sehingga hasil akhir dengan menggabungkan metode didapatkan jumlah pesanan untuk masing-masing supplier [2].

\section{METODE PENELITIAN}

\subsection{Penentuan Decision Maker}

Decision maker adalah para ahli yang menangani pengadaan wrapping and flavour di PT. Djarum Kudus. Para ahli memiliki pengetahuan dan pengalaman yang berhubungan dengan kriteria dan pemilihan supplier serta permasalahan pada bagian pengadaan wrapping and flavour. Decision maker ini akan menjadi responden dalam pengisian kuisioner. Decision maker dalam penelitian ini sebanyak 5 orang yang berada di bagian departemen pengadaan wrapping and flavour.

\subsection{Penentuan Kriteria Supplier}

Pada tahap ini dilakukan penentuan kriteria dalam melakukan penentuan prioritas supplier pada PT. Djarum Kudus. Dalam melakukan pesanan order kepada supplier PT. Djarum Kudus menggunakan empat kriteria yaitu kemampuan teknis supplier, kapasitas produksi atau pasokan supplier, harga, dan rapor performansi. Rapor performansi terdiri dari empat kriteria yaitu delivery, quality, sevice, dan quantity fulfillment. Terdapat 23 kriteria penting dalam melakukan penentuan prioritas supplier [3]. Namun 23 kriteria tersebut disesuaikan dengan situasi dan lingkungan pengadaan perusahaan. Sehingga dalam melakukan penentuan prioritas supplier diperlukan informasi kriteria-kriteria dari peneliti lain. Rouyendegh (2013) menggunakan 17 kriteria untuk melakukan pemilihan supplier [2].

Berdasarkan hasil wawancara dengan pihak pengambil keputusan PT. Djarum Kudus dalam menentukan alokasi pesanan mengadopsi kriteria-kriteria pemilihan supplier hasil penelitian Rouyendegh (2013) yaitu terdiri atas 17 kriteria. Namun kriteria financial position tidak digunakan dalam penelitian ini dikarenakan adanya beberapa pertimbangan. Kriteria yang digunakan PT. Djarum Kudus dalam melakukan alokasi pesanan dapat dilihat pada Tabel 1. 
Tabel 1. Kriteria alokasi pesanan

\begin{tabular}{|c|c|c|}
\hline Kode & Kriteria & Penjelasan Kriteria \\
\hline $\mathrm{C} 1$ & Kapasitas Pasok & $\begin{array}{l}\text { Supplier dapat memelihara kebijakan persediaannya dan menjaga spare part } \\
\text { yang dimilikinya [4]. }\end{array}$ \\
\hline $\mathrm{C} 2$ & Kapasitas Produksi & Kemampuan produksi yang potensial pada masing-masing supplier [5]. \\
\hline $\mathrm{C} 3$ & Waktu Respon & $\begin{array}{l}\text { Waktu antara pesan dan penempatan material [5] atau kemampuan supplier } \\
\text { dalam merespon permintaan [6]. }\end{array}$ \\
\hline $\mathrm{C} 4$ & Teknologi Produksi & $\begin{array}{l}\text { Teknologi adalah kemajuan yang cepat dalam persaingan dunia untuk } \\
\text { memuaskan konsumen utama dan mendapatkan apresiasi [5]. }\end{array}$ \\
\hline $\mathrm{C} 5$ & Harga & $\begin{array}{l}\text { Harga merupakan salah satu faktor penentu konsumen dalam menentukan } \\
\text { suatu keputusan pembelian terhadap suatu produk maupun jasa [7]. }\end{array}$ \\
\hline C6 & Garansi & Jaminan yang diberikan supplier berkenaan atas produk yang dikirim [8]. \\
\hline $\mathrm{C} 7$ & Pemenuhan Prosedur & Prosedur yang harus dilalui buyer dalam mengajukan suatu komplain [8]. \\
\hline $\mathrm{C} 8$ & Transaksi Pembelian & Prosedur order yang harus dilakukan oleh buyer [8]. \\
\hline C9 & Sistem Komunikasi & $\begin{array}{l}\text { Komunikasi dan negosiasi yang baik dengan supplier menentukan kerjasama } \\
\text { jangka panjang antara supplier dengan perusahaan [5]. }\end{array}$ \\
\hline $\mathrm{C} 10$ & Kualitas & $\begin{array}{l}\text { Dengan kualitas produk yang baik konsumen akan terpenuhi keinginan dan } \\
\text { kebutuhannya akan suatu produk [7]. }\end{array}$ \\
\hline $\mathrm{C} 11$ & $\begin{array}{l}\text { Kelengkapan Dokumen } \\
\text { Pengiriman }\end{array}$ & Dokumen-dokumen yang diperlukan oleh supplier dan buyer [8]. \\
\hline $\mathrm{C} 12$ & Kuantitas & $\begin{array}{l}\text { Jumlah pesanan oleh buyer [8]. Kuantitas berhubungan dengan bagian } \\
\text { produksi dalam memenuhi target order jangka pendek [9]. }\end{array}$ \\
\hline $\mathrm{C} 13$ & Ketepatan Waktu & $\begin{array}{l}\text { Kemampuan supplier untuk mengikuti jadwal yang telah ditetapkan adalah } \\
\text { kriteria utama untuk pemilihan [5]. Pengiriman yang tepat waktu maka akan } \\
\text { menjamin kelancaran lintasan produksi [9]. }\end{array}$ \\
\hline $\mathrm{C} 14$ & Lokasi & $\begin{array}{l}\text { Lokasi supplier dapat dianalisis secara tepat sebelum pemilihan. Lokasi } \\
\text { supplier dicek sebelum pemilihan dikarenakan hubungan jangka panjang } \\
\text { dapat menciptakan masalah dalam mensuplai produk [5]. }\end{array}$ \\
\hline $\mathrm{C} 15$ & Reputasi & $\begin{array}{l}\text { Reputasi supplier sebagai kepercayaan dari perusahaan bahwa supplier } \\
\text { adalah jujur dan memperhatikan pelanggannya. Jika suatu vendor } \\
\text { memandangi reputasi kerjanya supplier bagus, kepercayaan akan diberikan } \\
{[10] \text {. }}\end{array}$ \\
\hline $\mathrm{C} 16$ & $\begin{array}{l}\text { Manajemen dan } \\
\text { Organisasi }\end{array}$ & Terdapat struktur organisasi dari perusahaan supplier [8]. \\
\hline
\end{tabular}

\subsection{Membuat Kuisioner Penilaian Bobot Kepentingan Kriteria dan Supplier}

Kuisioner merupakan sejumlah pertanyaan tertulis yang akan dijawab responden mengenai kriteria terhadap pemilihan supplier. Kuisioner dibedakan menjadi dua yaitu untuk penilaian bobot kepentingan tiap kriteria dapat dilihat pada tabel 2 dan kuisioner untuk penilaian supplier dapat dilihat pada tabel 3.

Tabel 2. Skala linguistik untuk bobot kepentingan kriteria

\begin{tabular}{cc}
\hline Variabel Linguistik & Triangular Fuzzy Number \\
\hline Very Low & $0,0,0.1$ \\
Low & $0,0.1,0.3$ \\
Medium Low & $0.1,0.3,0.5$ \\
Medium & $0.3,0.5,0.7$ \\
Medium High & $0.5,0.7,0.9$ \\
High & $0.7,0.9,1.0$ \\
Very High & $0.9,1.0,1.0$ \\
\hline
\end{tabular}


Tabel 3. Skala linguistik untuk penilaian supplier

\begin{tabular}{cc}
\hline Variabel Linguistik & Triangular Fuzzy Number \\
\hline Very Poor & $0,0,1$ \\
Poor & $0,1,3$ \\
Medium Poor & $1,3,5$ \\
Fair & $3,5,7$ \\
Medium Good & $5,7,9$ \\
Good & $7,9,10$ \\
Very Good & $9,10,10$ \\
\hline
\end{tabular}

\subsection{Penyebaran Kuisioner Penilaian Bobot Kepentingan Kriteria Dan Supplier}

Pada tahap ini kuisioner dibagikan kepada responden, di mana reseponden tersebut sebanyak 5 orang yang ahli dalam bidang departemen purchasing wrapping and flavour.

\subsection{Pengolahan Data Dengan Metode Fuzzy-TOPSIS}

Fuzzy-TOPSIS digunakan untuk membuat penilaian mengenai kriteria intangible dari supplier sehingga ini dapat dipertimbangkan sebagai parameter untuk mengukur pemenuhan syarat dari masing-masing supplier. Berdasarkan kriteria intangible, supplier yang tepat dapat ditunjukan oleh rangking terbaik dengan closeness coefecient. Berikut merupakan langkah-langkah dalam melakukan pengolahan data dengan metode fuzzy- TOPSIS [2]:

1. Bangkitkan alternatif yang tersedia, tentukan kriteria, dan atur grup pengambil keputusan Dengan m: alternatif, $\mathrm{n}$ : kriteria dan $\mathrm{k}$ : pengambil keputusan

2. Pilih variabel linguistik yang tepat untuk bobot kepentingan kriteria $\left(w_{j}=l_{i j}, m_{i j}, u_{i j}\right)$ dan penilaian lingustik untuk alternatif tiap kriteria $\left(x_{i j}\right)$ menjadi TFN.

3. Agregasi bobot kriteria untuk mendapatkan bobot fuzzy agregasi tiap kriteria $C_{j}$ dan dapatkan penilaian fuzzy agregasi $x_{i j}$ dari alternatif $A_{i}$ di bawah kriteria $C_{j}$ dievaluasi oleh ahli atau pembuat keputusan.

$$
\begin{gathered}
\tilde{x}_{i j}=\frac{1}{k}\left(\tilde{x}_{i j}^{1}+\tilde{x}_{i j}^{2}+\ldots+\tilde{x}_{i j}^{k}\right) ; i=1,2, \ldots, m ; j=1,2, \ldots, n \\
\tilde{w}_{i j}=\frac{1}{k}\left(\tilde{w}_{j}{ }^{1}+\tilde{w}_{j}{ }^{2}+\ldots+\tilde{w}_{j}{ }^{k}\right) ; j=1,2, \ldots, n
\end{gathered}
$$

4. Buat matrik keputusan fuzzy

$$
\begin{aligned}
\tilde{D} & =\left|\begin{array}{llll}
C_{1} & C_{2} & \ldots & C_{n} \\
\tilde{x}_{11} & \tilde{x}_{12} & \ldots & \tilde{x}_{1 n} \\
\tilde{x}_{21} & \tilde{x}_{22} & \ldots & \tilde{x}_{2 n} \\
\tilde{x}_{m 1} & \tilde{x}_{m 2} & \ldots & \tilde{x}_{m n}
\end{array}\right| \\
\widetilde{w} & =\left(\tilde{w}_{1}, \tilde{w}_{2}, \ldots, \tilde{w}_{n}\right)
\end{aligned}
$$

5. Normalisasi matrik keputusan fuzzy

Normalisasi matrik keputusan dinotasikan dengan $\mathrm{R}$ yang diperoleh dari rumus:

$\widetilde{R}=\left(\tilde{r}_{i j}\right)_{m x n} ; i=1,2, \ldots, m ; j=1,2, \ldots, n$

Rumus di atas dapat dihitung dengan secara detail:

$\tilde{r}_{i j}=\left(\frac{l_{i j}}{U_{j}^{*}}, \frac{m_{i j}}{U_{j}^{*}}, \frac{U_{i j}}{U_{j}^{*}}\right)$, dimana $U_{j}^{*}=\max u_{i j}$

6. Buat matrik keputusan fuzzy ternormalisasi terbobot

Agar menjadi kepentingan yang berbeda tiap kriteria, kita dapat membuat matrik keputusan fuzzy ternormalisasi terbobot dengan:

$\tilde{V}=\left(\tilde{v}_{i j}\right)_{m x n} ; i=1,2, \ldots, m ; j=1,2, \ldots, n$

Di mana

$\tilde{v}_{i j}=\tilde{r}_{i j} x w_{j} ; i=1,2, \ldots, m ; j=1,2, \ldots, n$

7. Tentukan FPIS (Fuzzy Positive Ideal Solution) dan FNIS (Fuzzy Negative Ideal Solution)

Perhitungan didapatkan dari:

$S^{+}=\left(\tilde{v}_{1}^{+}, \tilde{v}_{2}^{+}, \ldots, \tilde{v}_{n}^{+}\right)$ 
$S^{-}=\left(\tilde{v}_{1}^{-}, \tilde{v}_{2}^{-}, \ldots, \tilde{v}_{n}^{-}\right)$

Di mana $\tilde{v}_{j}^{+}=\max \left(v_{i j 3}\right)$ dan $\tilde{v}_{j}^{-}=\min \left(v_{i j 1}\right)$ karena $\tilde{v}_{j}$ adalah TFN yang ternormalisasi terbobot $i=1,2, \ldots, m ; j=1,2, \ldots, n$

8. Hitung jarak masing-masing alternatif dari FPIS $\left(d^{+}\right)$dan FNIS $\left(d^{-}\right)$

Berdasarkan metode vertex, jarak antara dua triangular fuzzy number $A_{1}\left(l_{1}, m_{1}, u_{1}\right)$ dan $A_{2}\left(l_{2}, m_{2}, u_{2}\right)$ dapat dihitung sebagai:

$$
\begin{aligned}
& d\left(A_{1}, A_{2}\right)=\sqrt{\frac{1}{3}\left(\left(l_{1}-l_{2}\right)^{2}+\left(m_{1}-m_{2}\right)^{2}+\left(u_{1}-u_{2}\right)\right)} \\
& d_{i}^{+}=\sum_{j=1}^{n} d\left(\tilde{v}_{i j}, \tilde{v}_{j}^{+}\right) \\
& d_{i}^{-}=\sum_{j=1}^{n} d\left(\tilde{v}_{i j}, \tilde{v}_{j}^{-}\right)
\end{aligned}
$$

9. Hitung $C C_{i}$ (the Closeness coefficient) dan rangking pesanan alternatif berdasarkan koefesien

Setelah kita dapatkan jarak $d^{+}$dan $d$, kita menghitung the closeness coefecient masing-masing alternatif dengan menggunakan rumus:

$$
C C_{i}=\frac{d_{i}^{-}}{d_{i}^{+}+d_{i}^{-}} ; i=1,2, \ldots, m
$$

Berdasarkan nilai $C C_{i}$ masing-masing alternatif kita tentukan rangking pesanan dari semua alternatif yang $C C_{i}$ terbesar hingga $C C_{i}$ terkecil. Alternatif dengan $C C_{i}$ terbesar adalah yang terbaik.

\subsection{Pengolahan Data dengan Metode MCGP (Multi Choice Goal Programming)}

Berikut tahapan pengolahan data dengan menggunakan metode MCGP [2].

Tentukan fungsi tujuan

$$
\operatorname{Min} Z=d_{1}^{+}+d_{1}^{-}+d_{2}^{+}+d_{2}^{-}+d_{3}^{+}+d_{3}^{-}+d_{4}^{+}+d_{4}^{-}+e_{1}^{+}+e_{1}^{-}+e_{2}^{+}+e_{2}^{-}+e_{3}^{+}+e_{3}^{-}
$$

Tentukan tujuan dan batasan untuk minimasi total cost of purchasing

$$
\operatorname{Min} Z_{1}=\sum_{i=1}^{n} C C_{i} \cdot X_{i}+O_{i} Y_{i}
$$

Tentukan tujuan dan batasan untuk maksimasi total value of purchasing

$$
\operatorname{Min} Z_{2}=\sum_{i=1}^{n} C C_{i} \cdot X_{i}
$$

Tentukan tujuan dan batasan untuk minimasi jumlah cacat

$$
\operatorname{Min} Z_{3}=\sum_{i=1}^{n} q_{i} . X_{i}
$$

Tentukan tujuan dan batasan untuk minimasi jumlah keterlambatan

$$
\operatorname{Min} Z_{4}=\sum_{i=1}^{n} p_{i} \cdot X_{i}
$$

Tentukan batasan demand

$$
\sum_{i=1}^{n} X_{i}=D
$$

Tentukan batasan kapasitas

$$
X_{i} \leq S_{i} . Y_{i} \text { dimana } i=1,2, \ldots, n
$$

Tentukan batasan non negatif dan binary

$$
\begin{aligned}
& X_{i} \geq 0 \text { dan integer } ; i=1,2, \ldots, n \\
& Y_{i}=0 \text { atau } 1 ; i=1,2, \ldots, n
\end{aligned}
$$




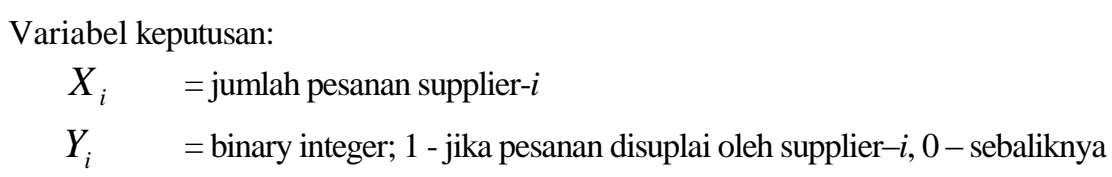

\section{HASIL PENELITIAN DAN PEMBAHASAN}

\subsection{Hasil Pengolahan Data Dengan Metode Fuzzy TOPSIS}

Setelah menyebarkan kuisioner maka langkah selanjutnya adalah melakukan pengolahan data dengan menggunakan metode fuzzy-TOPSIS untuk mendapatkan bobot kepentingan tiap kriteria dan rangking untuk tiap alternatif yang tersedia. Pengolahan data menggunakan metode fuzzy ini untuk semua jenis bahan baku plat bos. Dari hasil kuisioner yang dibagikan kepada ahli bagian departemen purchasing wrapping and flavour sebanyak 5 ahli, langkah selanjutnya adalah mengubah kuisioner menjadi Triangular Fuzzy Number. Di mana kuisioner menggunakan notasi 1-7 yang ditransformasikan menjadi Triangular Fuzzy Number. Setelah dilakukan transformasi menjadi bilangan triangular fuzzy number untuk kepentingan tiap kriteria dan penilaian kinerja supplier maka langkah selanjutnya adalah agregasi bobot fuzzy kriteria dan penilaian fuzzy alternatif. Setelah melakukan agregasi bobot fuzzy untuk tiap kriteria dan penilaian alternatif maka langkah selanjutnya adalah membuat matriks keputusan fuzzy yang dapat dilihat pada tabel 4. Di mana matriks keputusan fuzzy adalah gabungan dari agregasi bobot fuzzy untuk tiap kriteria dan penilaian alternatif. Perhitungan agregasi bobot fuzzy kriteria menggunakan persamaan (2) dan perhitungan agregasi penilaian fuzzy alternatif menggunakan menggunakan persamaan (1).

Setelah membuat membuat matriks keputusan fuzzy berikutnya adalah menyusun matriks keputusan fuzzy yang ternormalisasi seperti ditunjukkan pada tabel 5. Perhitungan menggunakan persamaan (4) dan (5). Berikutnya adalah membuat matriks keputusan fuzzy yang ternormalisasi terbobot. Perhitungan menggunakan persamaan (6) dan (7). Matriks keputusan fuzzy yang ternomalisasi terbobot, dapat dilihat pada tabel 6.

Tabel 4. Matriks keputusan fuzzy

\begin{tabular}{|c|c|c|c|c|c|c|c|c|c|c|c|c|c|c|c|}
\hline \multirow{3}{*}{ Kriteria } & \multirow{2}{*}{\multicolumn{4}{|c|}{ Bobot Kriteria }} & \multicolumn{11}{|c|}{ Alternatif } \\
\hline & & & & & \multicolumn{2}{|c|}{$A 1$} & \multicolumn{3}{|c|}{$A 2$} & \multicolumn{3}{|c|}{$A 3$} & \multicolumn{3}{|c|}{$A 4$} \\
\hline & $L$ & $M$ & $u$ & $l$ & $m$ & $U$ & $l$ & $m$ & $u$ & $l$ & $m$ & $u$ & $l$ & $m$ & $u$ \\
\hline $\mathrm{C} 1$ & 0.78 & 0.92 & 0.98 & 5.4 & 7.2 & 8.4 & 6.2 & 8 & 9.4 & 7 & 8.8 & 9.8 & 7.4 & 9 & 9.8 \\
\hline $\mathrm{C} 2$ & 0.82 & 0.96 & 1 & 5.4 & 7.4 & 8.8 & 5.4 & 7.4 & 9 & 6.2 & 8.2 & 9.4 & 6.6 & 8.4 & 9.6 \\
\hline $\mathrm{C} 3$ & 0.74 & 0.9 & 0.98 & 5.4 & 7.4 & 8.8 & 5.4 & 7.4 & 9 & 6.2 & 8.2 & 9.4 & 6.2 & 8.2 & 9.6 \\
\hline $\mathrm{C} 4$ & 0.66 & 0.82 & 0.92 & 5.4 & 7.4 & 9 & 5.8 & 7.8 & 9.2 & 5 & 7 & 8.6 & 5 & 7 & 8.6 \\
\hline $\mathrm{C} 5$ & 0.78 & 0.92 & 0.98 & 5.4 & 7.4 & 9 & 4.2 & 6.2 & 8 & 5.8 & 7.8 & 9.2 & 4.6 & 6.6 & 8.4 \\
\hline C6 & 0.7 & 0.86 & 0.96 & 4.6 & 6.6 & 8.2 & 5 & 7 & 8.6 & 4.4 & 6.2 & 7.8 & 5.4 & 7.4 & 9 \\
\hline C7 & 0.62 & 0.8 & 0.92 & 5 & 7 & 8.6 & 5.4 & 7.4 & 9 & 5.4 & 7.4 & 9 & 5.4 & 7.4 & 9 \\
\hline $\mathrm{C} 8$ & 0.7 & 0.88 & 0.98 & 6.6 & 8.4 & 9.6 & 6.2 & 8 & 9.2 & 7 & 8.8 & 9.8 & 6.6 & 8.4 & 9.6 \\
\hline C9 & 0.58 & 0.78 & 0.92 & 7.8 & 9.4 & 10 & 6.6 & 8.6 & 9.8 & 7 & 8.8 & 9.8 & 7.8 & 9.4 & 10 \\
\hline $\mathrm{C} 10$ & 0.86 & 0.98 & 1 & 5.8 & 7.6 & 9 & 5 & 6.8 & 8.2 & 7.4 & 9 & 9.8 & 6.2 & 8 & 9.2 \\
\hline C11 & 0.78 & 0.94 & 1 & 6.2 & 8 & 9.2 & 6.6 & 8.4 & 9.6 & 6.6 & 8.4 & 9.6 & 6.6 & 8.4 & 9.6 \\
\hline $\mathrm{C} 12$ & 0.74 & 0.88 & 0.96 & 5.8 & 7.8 & 9.2 & 6.2 & 8.2 & 9.6 & 6.6 & 8.4 & 9.4 & 5.4 & 7.4 & 8.8 \\
\hline $\mathrm{C} 13$ & 0.9 & 1 & 1 & 5.4 & 7.2 & 8.6 & 5.8 & 7.6 & 9 & 7 & 8.6 & 9.4 & 6.2 & 8 & 9.2 \\
\hline C14 & 0.46 & 0.66 & 0.82 & 8.2 & 9.6 & 10 & 7.8 & 9.2 & 9.8 & 7.4 & 8.8 & 9.4 & 7.4 & 8.8 & 9.4 \\
\hline C15 & 0.54 & 0.72 & 0.86 & 6.6 & 8.4 & 9.4 & 6.2 & 8 & 9.2 & 7 & 8.8 & 9.8 & 7 & 8.6 & 9.4 \\
\hline $\mathrm{C} 16$ & 0.62 & 0.82 & 0.96 & 5.4 & 7.4 & 9 & 3.8 & 5.8 & 7.8 & 5 & 7 & 8.6 & 5.4 & 7.4 & 9 \\
\hline
\end{tabular}


Tabel 5. Matriks keputusan fuzzy yang ternormalisasi

\begin{tabular}{|c|c|c|c|c|c|c|c|c|c|c|c|c|}
\hline \multirow{3}{*}{ Kriteria } & \multicolumn{12}{|c|}{ Alternatif } \\
\hline & \multirow{2}{*}{\multicolumn{3}{|c|}{$\frac{A 1}{m}$}} & \multicolumn{3}{|c|}{$A 2$} & \multicolumn{4}{|c|}{$A 3$} & \multicolumn{2}{|c|}{$A 4$} \\
\hline & & & & $L$ & $m$ & $U$ & $l$ & $m$ & $u$ & $l$ & $m$ & $u$ \\
\hline $\mathrm{C} 1$ & 0.55 & 0.73 & 0.86 & 0.63 & 0.82 & 0.96 & 0.71 & 0.90 & 1.00 & 0.76 & 0.92 & 1.00 \\
\hline $\mathrm{C} 2$ & 0.56 & 0.77 & 0.92 & 0.56 & 0.77 & 0.94 & 0.65 & 0.85 & 0.98 & 0.69 & 0.88 & 1.00 \\
\hline C3 & 0.56 & 0.77 & 0.92 & 0.56 & 0.77 & 0.94 & 0.65 & 0.85 & 0.98 & 0.65 & 0.85 & 1.00 \\
\hline $\mathrm{C} 4$ & 0.59 & 0.80 & 0.98 & 0.63 & 0.85 & 1.00 & 0.54 & 0.76 & 0.93 & 0.54 & 0.76 & 0.93 \\
\hline C5 & 0.59 & 0.80 & 0.98 & 0.46 & 0.67 & 0.87 & 0.63 & 0.85 & 1.00 & 0.50 & 0.72 & 0.91 \\
\hline C6 & 0.51 & 0.73 & 0.91 & 0.56 & 0.78 & 0.96 & 0.49 & 0.69 & 0.87 & 0.60 & 0.82 & 1.00 \\
\hline C7 & 0.56 & 0.78 & 0.96 & 0.60 & 0.82 & 1.00 & 0.60 & 0.82 & 1.00 & 0.60 & 0.82 & 1.00 \\
\hline $\mathrm{C} 8$ & 0.67 & 0.86 & 0.98 & 0.63 & 0.82 & 0.94 & 0.71 & 0.90 & 1.00 & 0.67 & 0.86 & 0.98 \\
\hline C9 & 0.78 & 0.94 & 1.00 & 0.66 & 0.86 & 0.98 & 0.70 & 0.88 & 0.98 & 0.78 & 0.94 & 1.00 \\
\hline $\mathrm{C} 10$ & 0.59 & 0.78 & 0.92 & 0.51 & 0.69 & 0.84 & 0.76 & 0.92 & 1.00 & 0.63 & 0.82 & 0.94 \\
\hline $\mathrm{C} 11$ & 0.65 & 0.83 & 0.96 & 0.69 & 0.88 & 1.00 & 0.69 & 0.88 & 1.00 & 0.69 & 0.88 & 1.00 \\
\hline $\mathrm{C} 12$ & 0.60 & 0.81 & 0.96 & 0.65 & 0.85 & 1.00 & 0.69 & 0.88 & 0.98 & 0.56 & 0.77 & 0.92 \\
\hline $\mathrm{C} 13$ & 0.57 & 0.77 & 0.91 & 0.62 & 0.81 & 0.96 & 0.74 & 0.91 & 1.00 & 0.66 & 0.85 & 0.98 \\
\hline C14 & 0.82 & 0.96 & 1.00 & 0.78 & 0.92 & 0.98 & 0.74 & 0.88 & 0.94 & 0.74 & 0.88 & 0.94 \\
\hline C15 & 0.67 & 0.86 & 0.96 & 0.63 & 0.82 & 0.94 & 0.71 & 0.90 & 1.00 & 0.71 & 0.88 & 0.96 \\
\hline $\mathrm{C} 16$ & 0.60 & 0.82 & 1.00 & 0.42 & 0.64 & 0.87 & 0.56 & 0.78 & 0.96 & 0.60 & 0.82 & 1.00 \\
\hline
\end{tabular}

Setelah membuat matriks keputusan fuzzy yang ternormalisasi terbobot, langkah selanjutnya adalah menentukan solusi ideal positif dan solusi ideal negatif. Di mana untuk solusi ideal positif adalah maksimasi TFN yang ternormalisasi terbobot untuk tiap kriteria, sedangkan solusi ideal negatif adalah minimasi TFN yang ternormalisasi terbobot untuk tiap kriteria. Perhitungan menggunakan persamaan (8) dan (9).

Menentukan solusi ideal positif (FPIS) dan solusi ideal negatif (FNIS)

$S^{+}=[(0.98,0.98,0.98), \quad(1,1,1), \quad(0.98,0.98,0.98), \quad(0.92,0.92,0.92), \quad(0.98,0.98,0.98), \quad(0.96,0.96,0.96)$, (0.92,0.92,0.92), (0.98,0.98,0.98), (0.92,0.92,0.92), (1,1,1), (1,1,1), (0.96,0.96,0.96), (1,1,1), (0.82,0.82,0.82), $(0.86,0.86,0.86),(0.96,0.96,0.96)]$

$S^{-}=[(0.43,0.43,0.43),(0.46,0.46,0.46),(0.42,0.42,0.42),(0.36,0.36,0.36),(0.36,0.36,0.36),(0.34,0.34,0.34)$, $(0.34,0.34,0.34), \quad(0.44,0.44,0.44), \quad(0.38,0.38,0.38), \quad(0.44,0.44,0.44), \quad(0.5,0.5,0.5), \quad(0.42,0.42,0.42)$, $(0.52,0.52,0.52),(0.34,0.34,0.34),(0.34,0.34,0.34),(0.26,0.26,0.26)]$

Langkah selanjutnya adalah menghitung jarak masing-masing alternatif supplier antara nilai FPIS dan FNIS. Hasil jarak FPIS dan FNIS dapat dilihat pada tabel 7. Tabel 8 merupakan jarak masing-masing $d^{+}$dan $d^{-} \cdot d^{+}$adalah jumlah keseluruhan FPIS tiap alternatif dan $d^{-}$adalah jumlah keseluruhan FNIS tiap alternatif. Perhitungannya menggunakan persamaan (30) dan (31).

Tabel 6. Matriks keputusan fuzzy yang ternomalisasi terbobot

\begin{tabular}{|c|c|c|c|c|c|c|c|c|c|c|c|c|}
\hline \multirow{3}{*}{ Kriteria } & \multicolumn{12}{|c|}{ Alternatif } \\
\hline & \multirow{2}{*}{\multicolumn{3}{|c|}{$\frac{A 1}{m}$}} & \multicolumn{3}{|c|}{$A 2$} & \multicolumn{3}{|c|}{$A 3$} & \multicolumn{3}{|c|}{$A 4$} \\
\hline & & & & $L$ & $M$ & $\boldsymbol{u}$ & $l$ & $m$ & $u$ & $l$ & $m$ & $u$ \\
\hline $\mathrm{C} 1$ & 0.43 & 0.68 & 0.84 & 0.49 & 0.75 & 0.94 & 0.56 & 0.83 & 0.98 & 0.59 & 0.84 & 0.98 \\
\hline $\mathrm{C} 2$ & 0.46 & 0.74 & 0.92 & 0.46 & 0.74 & 0.94 & 0.53 & 0.82 & 0.98 & 0.56 & 0.84 & 1.00 \\
\hline C3 & 0.42 & 0.69 & 0.90 & 0.42 & 0.69 & 0.92 & 0.48 & 0.77 & 0.96 & 0.48 & 0.77 & 0.98 \\
\hline $\mathrm{C} 4$ & 0.39 & 0.66 & 0.90 & 0.42 & 0.70 & 0.92 & 0.36 & 0.62 & 0.86 & 0.36 & 0.62 & 0.86 \\
\hline $\mathrm{C} 5$ & 0.46 & 0.74 & 0.96 & 0.36 & 0.62 & 0.85 & 0.49 & 0.78 & 0.98 & 0.39 & 0.66 & 0.89 \\
\hline C6 & 0.36 & 0.63 & 0.87 & 0.39 & 0.67 & 0.92 & 0.34 & 0.59 & 0.83 & 0.42 & 0.71 & 0.96 \\
\hline C7 & 0.34 & 0.62 & 0.88 & 0.37 & 0.66 & 0.92 & 0.37 & 0.66 & 0.92 & 0.37 & 0.66 & 0.92 \\
\hline $\mathrm{C} 8$ & 0.47 & 0.75 & 0.96 & 0.44 & 0.72 & 0.92 & 0.50 & 0.79 & 0.98 & 0.47 & 0.75 & 0.96 \\
\hline C9 & 0.45 & 0.73 & 0.92 & 0.38 & 0.67 & 0.90 & 0.41 & 0.69 & 0.90 & 0.45 & 0.73 & 0.92 \\
\hline $\mathrm{C} 10$ & 0.51 & 0.76 & 0.92 & 0.44 & 0.68 & 0.84 & 0.65 & 0.90 & 1.00 & 0.54 & 0.80 & 0.94 \\
\hline $\mathrm{C} 11$ & 0.50 & 0.78 & 0.96 & 0.54 & 0.82 & 1.00 & 0.54 & 0.82 & 1.00 & 0.54 & 0.82 & 1.00 \\
\hline $\mathrm{C} 12$ & 0.45 & 0.72 & 0.92 & 0.48 & 0.75 & 0.96 & 0.51 & 0.77 & 0.94 & 0.42 & 0.68 & 0.88 \\
\hline $\mathrm{C} 13$ & 0.52 & 0.77 & 0.91 & 0.56 & 0.81 & 0.96 & 0.67 & 0.91 & 1.00 & 0.59 & 0.85 & 0.98 \\
\hline $\mathrm{C} 14$ & 0.38 & 0.63 & 0.82 & 0.36 & 0.61 & 0.80 & 0.34 & 0.58 & 0.77 & 0.34 & 0.58 & 0.77 \\
\hline C15 & 0.36 & 0.62 & 0.82 & 0.34 & 0.59 & 0.81 & 0.39 & 0.65 & 0.86 & 0.39 & 0.63 & 0.82 \\
\hline $\mathrm{C} 16$ & 0.37 & 0.67 & 0.96 & 0.26 & 0.53 & 0.83 & 0.34 & 0.64 & 0.92 & 0.37 & 0.67 & 0.96 \\
\hline
\end{tabular}


Tabel 7. Jarak antara fpis dan fnis dan penilaian alternatif

\begin{tabular}{ccccccccc}
\hline Kriteria & \multicolumn{4}{c}{$\boldsymbol{F P I S}$} & \multicolumn{5}{c}{$\boldsymbol{F N I S}$} \\
\cline { 2 - 9 } & $\boldsymbol{A 1}$ & $\boldsymbol{A 2}$ & $\boldsymbol{A 3}$ & $\boldsymbol{A 4}$ & $\boldsymbol{A 1}$ & $\boldsymbol{A 2}$ & $\boldsymbol{A 3}$ & $\boldsymbol{A 4}$ \\
\hline C1 & 0.37 & 0.31 & 0.26 & 0.24 & 0.28 & 0.35 & 0.40 & 0.41 \\
C2 & 0.35 & 0.35 & 0.29 & 0.27 & 0.31 & 0.32 & 0.37 & 0.38 \\
C3 & 0.37 & 0.37 & 0.31 & 0.31 & 0.32 & 0.33 & 0.38 & 0.39 \\
C4 & 0.34 & 0.32 & 0.37 & 0.37 & 0.36 & 0.38 & 0.33 & 0.33 \\
C5 & 0.33 & 0.42 & 0.30 & 0.39 & 0.42 & 0.32 & 0.44 & 0.36 \\
C6 & 0.40 & 0.37 & 0.42 & 0.34 & 0.35 & 0.38 & 0.32 & 0.42 \\
C7 & 0.37 & 0.35 & 0.35 & 0.35 & 0.35 & 0.38 & 0.38 & 0.38 \\
C8 & 0.32 & 0.35 & 0.30 & 0.32 & 0.35 & 0.32 & 0.37 & 0.35 \\
C9 & 0.29 & 0.34 & 0.33 & 0.29 & 0.37 & 0.34 & 0.35 & 0.37 \\
C10 & 0.32 & 0.38 & 0.21 & 0.29 & 0.34 & 0.27 & 0.44 & 0.36 \\
C11 & 0.31 & 0.29 & 0.29 & 0.29 & 0.31 & 0.34 & 0.34 & 0.34 \\
C12 & 0.33 & 0.30 & 0.28 & 0.36 & 0.34 & 0.37 & 0.37 & 0.31 \\
C13 & 0.31 & 0.28 & 0.20 & 0.25 & 0.27 & 0.31 & 0.37 & 0.33 \\
C14 & 0.28 & 0.29 & 0.31 & 0.31 & 0.33 & 0.31 & 0.28 & 0.28 \\
C15 & 0.32 & 0.34 & 0.30 & 0.30 & 0.32 & 0.30 & 0.35 & 0.33 \\
C16 & 0.38 & 0.48 & 0.40 & 0.38 & 0.47 & 0.36 & 0.44 & 0.47 \\
\hline
\end{tabular}

Tabel 8. Jarak masing - masing $d^{+}$dan $d$

\begin{tabular}{ccc} 
Alternatif & $d^{+}$ & $d^{-}$ \\
\hline A1 & 5.40 & 5.47 \\
A2 & 5.54 & 5.39 \\
A3 & 4.92 & 5.91 \\
A4 & 5.06 & 5.81 \\
\hline
\end{tabular}

Setelah kita dapatkan jarak $d^{+}$dan $d^{-}$, kita menghitung the closeness coefecient masing-masing alternatif. Hasil perangkingan dapat dilihat pada Tabel 9. Perhitungan menggunakan persamaan (12)

Tabel 9. $C C_{i}$ dan rangking alternatif

\begin{tabular}{rrr}
\hline Alternatif & $\boldsymbol{C C}_{\boldsymbol{i}}$ & \multicolumn{1}{c}{ Rank } \\
\hline $\mathrm{A} 1$ & 0.50 & 3 \\
$\mathrm{~A} 2$ & 0.49 & 4 \\
$\mathrm{~A} 3$ & 0.55 & 1 \\
$\mathrm{~A} 4$ & 0.53 & 2 \\
\hline
\end{tabular}

\subsection{Pengolahan Data Dengan Metode MCGP (Multi Choice Goal Programming)}

1. Plat bos DC 12 IDN R1

Fungsi Tujuan

$\operatorname{Min} Z=d_{1}^{+}+d_{1}^{-}+d_{2}^{+}+d_{2}^{-}+d_{3}^{+}+d_{3}^{-}+d_{4}^{+}+d_{4}^{-}+e_{1}^{+}+e_{1}^{-}+e_{2}^{+}+e_{2}^{-}+e_{3}^{+}+e_{3}^{-}$

s.t

Tujuan dan Batasan untuk Minimasi Total Cost of Purchasing

$\sum_{i=1}^{n} C_{i} \cdot A_{i}+O_{i} Y_{i}+d_{j}^{-}-d_{j}^{+}=y_{t}$

$60 A_{1}+2000 Y_{1}+65 A_{2}+2000 Y_{2}+58 A_{3}+2000 Y_{3}+73 A_{4}+2000 Y_{4}+d_{1}^{+}-d_{1}^{-}=y_{1}$

$y_{1}-e_{1}^{+}+e_{1}^{-}=12.172 .000$

$12.172 .000 \leq y_{1} \leq 27.652 .800$

Tujuan dan Batasan untuk Maksimasi Total Value of Purchasing

$\sum_{i=1}^{n} C C_{i} \cdot A_{i}+d_{j}{ }^{-}-d_{j}{ }^{+} \geq V$

$0,50 A_{1}+0,49 A_{2}+0,55 A_{3}+0,53 A_{4}+d_{2}^{+}-d_{2}^{-} \geq 90.000$ 
Tujuan dan Batasan untuk Minimasi Jumlah Cacat

$\sum_{i=1}^{n} q_{i} \cdot A_{i}+d_{j}^{-}-d_{j}^{+}=y_{t}$

$0,35 A_{1}+0,71 A_{2}+0 A_{3}+0 A_{4}+d_{3}^{+}-d_{3}^{-}=y_{2}$

$y_{t}-e_{t}^{+}+e_{t}^{-}=Q_{\min } . D$

$y_{2}-e_{2}^{+}+e_{2}^{-}=0 \times 800.000$

$Q_{\min } \cdot D \leq y_{2} \leq Q_{\max } \cdot D$

$0 \times 800.000 \leq y_{2} \leq 0,38 \times 584.000$

Tujuan dan Batasan untuk Minimasi Jumlah Keterlambatan

$\sum_{i=1}^{n} p_{i} \cdot A_{i}+d_{j}^{-}-d_{j}^{+}=y_{t}$

$1 A_{1}+0 A_{2}+0 A_{3}+0 A_{4}+d_{4}^{+}-d_{4}^{-}=y_{3}$

$y_{t}-e_{t}^{+}+e_{t}^{-}=P_{\min } . D$

$y_{3}-e_{3}{ }^{+}+e_{3}^{-}=0 \times 800.000$

$P_{\text {min }} \cdot D \leq y_{3} \leq P_{\max } \cdot D$

$0 \times 800.000 \leq y_{3} \leq 0,05 \times 800.000$

Batasan Demand

$\sum_{i=1}^{n} A_{i}=D$

$A_{1}+A_{2}+A_{3}+A_{4}=800.000$

Batasan Kapasitas

$X_{i} \leq S_{i} \cdot Y_{i}$

$A_{1} \leq 1.200 .000$

$Y_{1} . A_{2} \leq 950.000$

$Y_{2} \cdot A_{3} \leq 1.000 .000$

$Y_{3} . A_{4} \leq 1.000 .000 \times Y_{4}$

Batasan Non Negatif dan Binary

$A_{1}, A_{2}, A_{3}, A_{4} \geq 0$ dan integer

$Y_{1}, Y_{2}, Y_{3}, Y_{4}=0$ atau 1

$d_{1}^{+}, d_{1}^{-}, d_{2}^{+}, d_{2}^{-}, d_{3}^{+}, d_{3}^{-}, d_{4}^{+}, d_{4}^{-} \geq 0$

$e_{1}^{+}+e_{1}^{-}+e_{2}^{+}+e_{2}^{-}+e_{3}^{+}+e_{3}^{-} \geq 0$

Dengan menggunakan software LINGO 13, solusi optimal dengan A1=0; A2=0; A3=800,000; A4=0. Pencapaian tujuan untuk tujuan pertama total cost of purchasing sebesar 46,402,000; tujuan kedua adalah total value of purchasing sebesar 440,000; tujuan ketiga adalah total jumlah cacat pengiriman sebesar 0 unit, dan tujuan keempat adalah total jumlah pengiriman yang telat sebesar 0 unit. Sehingga didapat bahwa fungsi tujuan Min $\mathrm{Z}$ adalah sebesar 68,810,000.

2. Plat bos DCX 12 IDN

Fungsi Tujuan

$\operatorname{Min} Z=d_{1}^{+}+d_{1}^{-}+d_{2}^{+}+d_{2}^{-}+d_{3}^{+}+d_{3}^{-}+d_{4}^{+}+d_{4}^{-}+e_{1}^{+}+e_{1}^{-}+e_{2}^{+}+e_{2}^{-}+e_{3}^{+}+e_{3}^{-}$

s.t

Tujuan dan Batasan untuk Minimasi Total Cost of Purchasing

$\sum_{i=1}^{n} C_{i} \cdot X_{i}+O_{i} Y_{i}+d_{j}^{-}-d_{j}^{+}=y_{t}$ 


$$
\begin{aligned}
& 60 A_{1}+2000 Y_{1}+58 A_{2}+2000 Y_{2}+65 A_{3}+2000 Y_{3}+73 A_{4}+2000 Y_{4}+d_{1}^{+}-d_{1}^{-}=y_{1} \\
& \quad y_{1}-e_{1}^{+}+e_{1}^{-}=360.000 \\
& 360.000 \leq y_{1} \leq 360.000
\end{aligned}
$$

Tujuan dan Batasan untuk Maksimasi Total Value of Purchasing

$$
\begin{aligned}
& \sum_{i=1}^{n} C C_{i} \cdot A_{i}+d_{j}{ }^{-}-d_{j}{ }^{+} \geq V \\
& 0,50 A_{1}+0,49 A_{2}+0,55 A_{3}+0,53 A_{4}+d_{2}{ }^{+}-d_{2}{ }^{-} \geq 6.000
\end{aligned}
$$

Tujuan dan Batasan untuk Minimasi Jumlah Cacat

$$
\begin{aligned}
& \sum_{i=1}^{n} q_{i} \cdot A_{i}+d_{j}^{-}-d_{j}^{+}=y_{t} \\
& 0,35 A_{1}+0 A_{2}+0 A_{3}+0 A_{4}+d_{3}^{+}-d_{3}^{-}=y_{2} \\
& y_{t}-e_{t}^{+}+e_{t}^{-}=Q_{\min } \cdot D \\
& y_{2}-e_{2}^{+}+e_{2}^{-}=0 \times 6.000 \\
& Q_{\min } \cdot D \leq y_{2} \leq Q_{\max } \cdot D \\
& 0 \times 6.000 \leq y_{2} \leq 0,35 \times 6.000
\end{aligned}
$$

Tujuan dan Batasan untuk Minimasi Jumlah Keterlambatan

$$
\begin{aligned}
& \sum_{i=1}^{n} p_{i} \cdot A_{i}+d_{j}^{-}-d_{j}^{+}=y_{t} \\
& 0 A_{1}+0 A_{2}+0 A_{3}+0 A_{4}+d_{4}^{+}-d_{4}^{-}=y_{3} \\
& y_{t}-e_{t}^{+}+e_{t}^{-}=P_{\min } \cdot D \\
& y_{3}-e_{3}^{+}+e_{3}^{-}=0 \times 6.000 \\
& P_{\min } \cdot D \leq y_{3} \leq P_{\max } \cdot D \\
& 0 \times 6.000 \leq y_{3} \leq 0 \times 6.000
\end{aligned}
$$

Batasan Demand

$$
\sum_{i=1}^{n} A_{i}=D
$$$$
A_{1}+A_{2}+A_{3}+A_{4}=6.000
$$

Batasan Kapasitas

$X_{i} \leq S_{i} \cdot Y_{i}$

$A_{1} \leq 1.200 .000$

$Y_{1} \cdot A_{2} \leq 950.000$

$Y_{2} . A_{3} \leq 1.000 .000$

$Y_{3} . A_{4} \leq 1.000 .000 \times Y_{4}$

Batasan Non Negatif dan Binary

$A_{1}, A_{2}, A_{3}, A_{4} \geq 0$ dan integer

$Y_{1}, Y_{2}, Y_{3}, Y_{4}=0$ atau 1

$d_{1}^{+}, d_{1}^{-}, d_{2}{ }^{+}, d_{2}{ }^{-}, d_{3}{ }^{+}, d_{3}{ }^{-}, d_{4}{ }^{+}, d_{4}{ }^{-} \geq 0$

$e_{1}^{+}+e_{1}^{-}+e_{2}^{+}+e_{2}^{-}+e_{3}^{+}+e_{3}^{-} \geq 0$

Dengan menggunakan software LINGO 13, solusi optimal dengan A1=0; $\mathrm{A} 2=4,857 ; \mathrm{A} 3=1,143 ; \mathrm{A} 4=0$. Pencapaian tujuan untuk tujuan pertama total cost of purchasing sebesar 360,001; tujuan kedua adalah total value 
of purchasing sebesar 3,009 unit; tujuan ketiga adalah total jumlah cacat pengiriman sebesar 0 unit, dan tujuan keempat adalah total jumlah pengiriman yang telat sebesar 0 unit. Sehingga didapat bahwa fungsi tujuan Min $\mathrm{Z}$ adalah sebesar 2993,420.

\section{Plat bos SPR $12 \mathrm{IDN}$}

Fungsi Tujuan

$\operatorname{Min} Z=d_{1}^{+}+d_{1}^{-}+d_{2}^{+}+d_{2}^{-}+d_{3}^{+}+d_{3}^{-}+d_{4}^{+}+d_{4}^{-}+e_{1}^{+}+e_{1}^{-}+e_{2}^{+}+e_{2}^{-}+e_{3}^{+}+e_{3}^{-}$

s.t

Tujuan dan Batasan untuk Minimasi Total Cost of Purchasing

$$
\begin{aligned}
& \sum_{i=1}^{n} C_{i} \cdot X_{i}+O_{i} Y_{i}+d_{j}^{-}-d_{j}^{+}=y_{t} \\
& 53 A_{1}+2000 Y_{1}+55 A_{2}+2000 Y_{2}+60 A_{3}+2000 Y_{3}+58 A_{4}+2000 Y_{4}+d_{1}^{+}-d_{1}^{-}=y_{1} \\
& y_{1}-e_{1}^{+}+e_{1}^{-}=14.764 .500
\end{aligned}
$$

$14.764 .500 \leq y_{1} \leq 45.450 .000$

Tujuan dan Batasan untuk Maksimasi Total Value of Purchasing

$$
\begin{aligned}
& \sum_{i=1}^{n} C C_{i} \cdot A_{i}+d_{j}^{-}-d_{j}^{+} \geq V \\
& 0,50 A_{1}+0,49 A_{2}+0,55 A_{3}+0,53 A_{4}+d_{2}{ }^{+}-d_{2}{ }^{-} \geq 132.000
\end{aligned}
$$

Tujuan dan Batasan untuk Minimasi Jumlah Cacat

$\sum_{i=1}^{n} q_{i} \cdot A_{i}+d_{j}^{-}-d_{j}^{+}=y_{t}$

$0,14 A_{1}+0,28 A_{2}+0 A_{3}+0 A_{4}+d_{3}^{+}-d_{3}^{-}=y_{2}$

$y_{t}-e_{t}^{+}+e_{t}^{-}=Q_{\min } . D$

$y_{2}-e_{2}{ }^{+}+e_{2}{ }^{-}=0 \times 367.477$

$Q_{\min } . D \leq y_{2} \leq Q_{\max } . D$

$0 \times 367.477 \leq y_{2} \leq 0,19 \times 367.477$

Tujuan dan Batasan untuk Minimasi Jumlah Keterlambatan

$\sum_{i=1}^{n} p_{i} \cdot A_{i}+d_{j}^{-}-d_{j}^{+}=y_{t}$

$0,92 A_{1}+0,08 A_{2}+0 A_{3}+0 A_{4}+d_{4}^{+}-d_{4}^{-}=y_{3}$

$y_{t}-e_{t}^{+}+e_{t}^{-}=P_{\min } . D$

$y_{3}-e_{3}^{+}+e_{3}^{-}=0 \times 367,477$

$P_{\min } . D \leq y_{3} \leq P_{\max } . D$

$0 \times 367.477 \leq y_{3} \leq 0,06 \times 367.477$

Batasan Demand

$\sum_{i=1}^{n} A_{i}=D$

$A_{1}+A_{2}+A_{3}+A_{4}=367.477$

Batasan Kapasitas

$X_{i} \leq S_{i} . Y_{i}$

$A_{1} \leq 1.200 .000$

$Y_{1} . A_{2} \leq 950.000$ 


$$
\begin{aligned}
& Y_{2} \cdot A_{3} \leq 1.000 .000 \\
& Y_{3} \cdot A_{4} \leq 1.000 .000 x Y_{4} \\
& \text { Batasan Non Negatif dan Binary } \\
& A_{1}, A_{2}, A_{3}, A_{4} \geq 0 \text { dan integer } \\
& Y_{1}, Y_{2}, Y_{3}, Y_{4}=0 \text { atau } 1 \\
& d_{1}^{+}, d_{1}^{-}, d_{2}^{+}, d_{2}^{-}, d_{3}^{+}, d_{3}^{-}, d_{4}^{+}, d_{4}^{-} \geq 0 \\
& e_{1}^{+}+e_{1}^{-}+e_{2}^{+}+e_{2}^{-}+e_{3}^{+}+e_{3}^{-} \geq 0
\end{aligned}
$$

Dengan menggunakan software LINGO 13, solusi optimal dengan $\mathrm{A} 1=367,477 ; \mathrm{A} 2=0 ; \mathrm{A} 3=0 ; \mathrm{A} 4=0$. Pencapaian tujuan untuk tujuan pertama total cost of purchasing sebesar 19,478,277; tujuan kedua adalah total value of purchasing sebesar 183,738.46 unit; tujuan ketiga adalah total jumlah cacat pengiriman sebesar 51,446.78 unit, dan tujuan keempat adalah total jumlah pengiriman yang telat sebesar 338,078.77 unit. Sehingga didapat bahwa fungsi tujuan Min Z adalah sebesar 10,258,351.66.

\section{Plat bos BLKML 16 IDN}

\section{Fungsi Tujuan}

$\operatorname{Min} Z=d_{1}^{+}+d_{1}^{-}+d_{2}^{+}+d_{2}^{-}+d_{3}^{+}+d_{3}^{-}+d_{4}^{+}+d_{4}^{-}+e_{1}^{+}+e_{1}^{-}+e_{2}^{+}+e_{2}^{-}+e_{3}^{+}+e_{3}^{-}$

s.t

Tujuan dan Batasan untuk Minimasi Total Cost of Purchasing

$\sum_{i=1}^{n} C_{i} \cdot X_{i}+O_{i} Y_{i}+d_{j}^{-}-d_{j}^{+}=y_{t}$

$$
\begin{aligned}
& 52 A_{1}+2000 Y_{1}+55 A_{2}+2000 Y_{2}+53 A_{3}+2000 Y_{3}+50 A_{4}+2000 Y_{4}+d_{1}^{+}-d_{1}^{-}=y_{1} \\
& y_{1}-e_{1}^{+}+e_{1}^{-}=756.000 \\
& 756.000 \leq y_{1} \leq 1.872 .000
\end{aligned}
$$

Tujuan dan Batasan untuk Maksimasi Total Value of Purchasing

$$
\begin{aligned}
& \sum_{i=1}^{n} C C_{i} \cdot A_{i}+d_{j}{ }^{-}-d_{j}{ }^{+} \geq V \\
& 0,50 A_{1}+0,49 A_{2}+0,55 A_{3}+0,53 A_{4}+d_{2}{ }^{+}-d_{2}{ }^{-} \geq 12.000
\end{aligned}
$$

Tujuan dan Batasan untuk Minimasi Jumlah Cacat

$$
\begin{aligned}
& \sum_{i=1}^{n} q_{i} \cdot A_{i}+d_{j}^{-}-d_{j}^{+}=y_{t} \\
& 0,05 A_{1}+0 A_{2}+0 A_{3}+0 A_{4}+d_{3}^{+}-d_{3}^{-}=y_{2} \\
& y_{t}-e_{t}^{+}+e_{t}^{-}=Q_{\min } \cdot D \\
& y_{2}-e_{2}^{+}+e_{2}^{-}=0 \times 36.000 \\
& Q_{\min } \cdot D \leq y_{2} \leq Q_{\max } \cdot D \\
& 0 x 36.000 \leq y_{2} \leq 0,05 \times 36.000
\end{aligned}
$$

Tujuan dan Batasan untuk Minimasi Jumlah Keterlambatan

$$
\begin{aligned}
& \sum_{i=1}^{n} p_{i} \cdot A_{i}+d_{j}^{-}-d_{j}^{+}=y_{t} \\
& 0,78 A_{1}+0 A_{2}+0 A_{3}+0 A_{4}+d_{4}^{+}-d_{4}^{-}=y_{3} \\
& y_{t}-e_{t}^{+}+e_{t}^{-}=P_{\min } . D
\end{aligned}
$$




$$
\begin{aligned}
& y_{3}-e_{3}^{+}+e_{3}^{-}=0 \times 36.000 \\
& P_{\min } . D \leq y_{3} \leq P_{\max } . D \\
& 0 \times 36.000 \leq y_{3} \leq 0,78 \times 36.000
\end{aligned}
$$

Batasan Demand

$$
\sum_{i=1}^{n} A_{i}=D
$$$$
A_{1}+A_{2}+A_{3}+A_{4}=36.000
$$

$$
\begin{aligned}
& \text { Batasan Kapasitas } \\
& X_{i} \leq S_{i} \cdot Y_{i} \\
& A_{1} \leq 1.200 .000 \\
& Y_{1} \cdot A_{2} \leq 950.000 \\
& Y_{2} \cdot A_{3} \leq 1.000 .000 \\
& Y_{3} \cdot A_{4} \leq 1.000 .000 x Y_{4} \\
& \text { Batasan Non Negatif dan Binary } \\
& A_{1}, A_{2}, A_{3}, A_{4} \geq 0 \text { dan integer } \\
& Y_{1}, Y_{2}, Y_{3}, Y_{4}=0 \text { atau } 1 \\
& d_{1}^{+}, d_{1}^{-}, d_{2}^{+}, d_{2}^{-}, d_{3}^{+}, d_{3}^{-}, d_{4}^{+}, d_{4}^{-} \geq 0 \\
& e_{1}^{+}+e_{1}^{-}+e_{2}^{+}+e_{2}^{-}+e_{3}^{+}+e_{3}^{-} \geq 0
\end{aligned}
$$

Dengan menggunakan software LINGO 13, solusi optimal dengan $\mathrm{A} 1=0 ; \mathrm{A} 2=0 ; \mathrm{A} 3=0, \mathrm{~A} 4=36,000$. Pencapaian tujuan untuk tujuan pertama total cost of purchasing sebesar 1,802,000; tujuan kedua adalah total value of purchasing sebesar 19,080 unit; tujuan ketiga adalah total jumlah cacat pengiriman sebesar 0 unit, dan tujuan keempat adalah total jumlah pengiriman yang telat sebesar 0 unit. Sehingga didapat bahwa fungsi tujuan Min Z adalah sebesar 2,099,080.

\subsection{Analisis Hasil Pengolahan}

Dari hasil agregasi bobot fuzzy kriteria didapat bahwa nilai kriteria yang memiliki bobot tertinggi pertama adalah kriteria C13 yaitu ketepatan waktu sebesar $(0.9 ; 1 ; 1)$, kriteria yang memiliki bobot tertinggi kedua adalah C10 yaitu kualitas sebesar $(0.86 ; 0.98 ; 1)$, dan kriteria yang memiliki bobot tertinggi ketiga adalah C2 yaitu kapasitas produksi sebesar $(0.82 ; 0.96 ; 1)$ dan kriteria yang memiliki bobot terendah adalah $\mathrm{C} 14$ yaitu lokasi sebesar $(0.46$; $0.66 ; 0.82)$. Sehingga dapat diartikan bahwa ketepatan waktu supplier sangat mempengaruhi perusahaan dalam penentuan prioritas supplier lebih besar dibandingkan dengan bobot kepentingan dari kriteria lainnya.

Dengan menggunakan metode ini maka alternatif yang terpilih adalah alternatif yang memiliki jarak terdekat dengan solusi ideal dan jarak terjauh dengan solusi ideal negatif. Asumsi dasar metode ini adalah ketika solusi ideal positif tidak dapat dicapai, pembuat keputusan akan mencari solusi yang sedekat mungkin dengan solusi ideal positif. Diperoleh nilai bahwa urutan rangking dari yang terbesar hingga yang terkecil adalah supplier $\mathrm{C}$ dengan nilai kedekatan sebesar 0.55 , supplier D dengan nilai kedekatan sebesar 0.53 , supplier A dengan nilai kedekatan sebesar 0.5, dan terakhir adalah supplier B dengan nilai kedekatan sebesar 0.49. Masing-masing supplier memiliki nilai kedekatan atau $C C_{i}$ yang akan digunakan dalam melakukan pengolahan data MCGP (Multi Choice Goal Programming) untuk memaksimalkan nilai total value of purchasing.

Dengan mengalokasikan pesanan plat bos DC 12 IDN R1 kepada supplier C sebesar 800,000 unit maka akan mengeluarkan biaya sebesar 46,402,000 rupiah dengan value of purchasing sebesar 440,000 unit dan dengan jumlah cacat barang 0 unit serta jumlah keterlambatan sebesar 0 unit. Dengan mengalokasikan pesanan plat bos DCX 12 IDN kepada supplier B sebesar 4,857 unit dan supplier C sebesar 1,143 unit maka akan mengeluarkan biaya sebesar 360,001 rupiah dengan value of purchasing sebesar 3,009 unit dan dengan jumlah cacat barang 0 unit serta jumlah keterlambatan sebesar 0 unit. Dengan mengalokasikan pesanan plat bos SPR 12 IDN kepada supplier A sebesar 367,477 unit maka akan mengeluarkan biaya sebesar 19,478,277 rupiah dengan value of purchasing 
sebesar 183,738.46 unit dan dengan jumlah cacat barang 51,446.78 unit serta jumlah keterlambatan sebesar 338,078.77 unit. Dengan mengalokasikan pesanan plat bos BLKML 16 IDN kepada supplier D sebesar 36,000 unit maka akan mengeluarkan biaya sebesar 1,802,000 rupiah dengan value of purchasing sebesar 19,080 unit dan dengan jumlah cacat barang 0 unit serta jumlah keterlambatan sebesar 0 unit

\section{KESIMPULAN}

Kriteria yang digunakan PT. Djarum Kudus dalam melakukan penentuan prioritas supplier yaitu kapasitas pasok, kapasitas produksi, waktu respon, teknologi produksi, harga, garansi, pemenuhan prosedur, transaksi pembelian, sistem komunikasi, kualitas, kelengkapan dokumen pengiriman, kuantitas, ketepatan waktu, lokasi, reputasi, dan manajemen dan organisasi. Dari hasil pengolahan data didapat bahwa kriteria tertinggi pertama adalah kriteria ketepatan waktu, kriteria tertinggi kedua adalah kriteria kualitas, dan kriteria tertinggi ketiga adalah kriteria kapasitas produksi dan kriteria yang terendah adalah kriteria lokasi. Sehingga dapat diartikan bahwa ketepatan waktu supplier sangat mempengaruhi perusahaan dalam penentuan prioritas supplier lebih besar dibandingkan dengan kepentingan dari kriteria lainnya. Dari hasil pengolahan data didapat bahwa urutan prioritas dari terbesar hingga terkecil yaitu supplier C, supplier D, supplier A, dan yang terakhir adalah supplier B. Alokasi pesanan untuk masing-masing alternatif yaitu: permintaan plat bos DC 12 IDN R1 ini kepada supplier C sebesar 800,000 unit, permintaan plat bos DCX 12 IDN ini kepada supplier B sebesar 4,857 unit dan supplier C sebesar 1,143 unit, permintaan plat bos SPR 12 IDN ini kepada supplier A sebesar 367,477 unit, permintaan plat bos BLKML 16 IDN ini kepada supplier D sebesar 36,000 unit. Hasil dari penelitian ini akan diberikan kepada PT. Djarum Kudus sebagai rekomendasi yaitu terdiri dari kriteria yang dibutuhkan dalam pemilihan supplier antara lain kapasitas pasok, kapasitas produksi, waktu respon, teknologi produksi, harga, garansi, pemenuhan prosedur, transaksi pembelian, sistem komunikasi, kualitas, kelengkapan dokumen pengiriman, kuantitas, ketepatan waktu, lokasi, reputasi, dan manajemen dan organisasi. Serta alokasi pesanan untuk plat bos DC 12 IDN R1 diberikan kepada supplier C, plat bos DCX 12 IDN diberikan kepada supplier B dan C, plat bos SPR 12 IDN diberikan kepada supplier A, dan plat bos BLKML 16 IDN diberikan kepada supplier D.

\section{DAFTAR PUSTAKA}

[1] Shodiqi, I.A., 2012. "Pemilihan Supplier dengan Mengintegrasikan Cluster Analysis, ANP, dan TOPSIS serta Alokasi Order dengan Beberapa Fungsi Tujuan”. Master Thesis of Industrial Engineering , RTI 658.403 Shop, 2012.

[2] Rouyendegh, B.D., dan Saputro, T.E. 2014. "Supplier Selection Using Integrated Fuzzy TOPSIS and MCGP: a Case Study". International Journal of Social and Behavioral Science 116, pp. 3957-3970.

[3] Imeri. 2013. 'Key Performance Criteria for Vendor Selection-A Literature Review'. International Journal of Management Research and Practice. Volume 5 Issue 2, pp. 63-75

[4] Sartin, 2012. 'Pemilihan Supplier Bahan Baku dengan Menggunakan Metode Multi Criteria Decision Making (MCDM) with Promethee dan Goal Programming di Perusahaan Azam Jaya Sidoarjo'. Jurnal Tekmapro UPI.

[5] Singh, R., dan Sharma, S.K., 2011. "Supplier Selection: Fuzzy AHP Approach. International Journal of Engineering Science and Technology", Vol. 3, No. 10

[6] Jannah, M., Fakhry, M., dan Rakhmawati. 2011. "Pengambilan Keputusan untuk Pemilihan Supplier Bahan Baku dengan Pendekatan Analytic Hierarchy Process di Perusahaan Pahala Sidoarjo". Agrointek Volume 5, No. 2., hal. 88-97

[7] Larosa, S.R., dan Sugiarto, Y. 2011. "Analisis Pengaruh Harga, Kualitas Produk, dan Lokasi terhadap Keputusan Pembelian”. Hal. 1-25 http://eprints.undip.ac.id/28746/1/Jurnal.pdf

[8] Rahman, M.I. dan Suparno, 2011. Seleksi Supplier dan Alokasi Order Bahan Baku dengan Pendekatan Fuzzy Analytic Network Process serta Goal Programming (Studi Kasus PT. IGLAS (Persero). Universitas Institut Teknologi Surabaya: Surabaya http://digilib.its.ac.id/public/ITS-Master-18889-9109201307-Presentation.pdf

[9] Kurniawati, D., Yuliando, H., dan Widodo, K.H. 2013. "Kriteria Pemilihan Pemasok Menggunakan Analytical Process". Jurnal Teknik Industri, Vol. 15,. No. 1, hal.25-32.

[10] Indarjo, M. 2002. "Proses Pengembangan Komimen Hubungan Pemasaran Jangka Panjang". Jurnal Sains Pemasaran Indonesia. Volume I, No. 2, hal. 152-161. 